\title{
Careful choices, shallower pockets and halted juggernauts
}

\author{
Stephen Hancocks \\ Editor-in-Chief
}

The very latest date on which the next UK General Election can be held is Thursday 3 June 2010. So, while the saying has it that 24 hours is a long time in politics, the 9,384 hours between now and then could well seem an eternity; except that since life rattles past us at such a break-neck speed nowadays it will be here in a twinkling. Consequently, by this time next year we will either already have a new government or we will be in the dying throws of an election campaign.

For whichever party wins that election, a number of choices will already have been dictated due to the overarching financial situation. The recent Budget made chilling listening as the Chancellor of the Exchequer read through the horrors of the UK's future borrowing requirements and the newspapers then graphically illustrated the length of time it will take to repay the debts; into the second quarter of this century assuming that things do not get any worse. I speculated in this column some time ago that the recession might well begin to affect spending at the higher end of the dental market as the year progressed. Although there are reports of a slight slowdown in the pace of attendances, thankfully the overall situation does not seem to be too bad. Discretionary spending on the more expensive treatments does seem to be being reined back somewhat but people clearly are still prepared to afford the options that make them look and feel better. Perhaps there is a type of reverse psychology at work during bad economic times.

\section{BE HONEST WHEN YOU ANSWER}

However, the longer term health of dentistry as a profession in this country may have less to do with the immediate game of numbers and more with the way in which public borrowing shapes the decision making processes in government. Much of the election is likely to be taken up with the parties trading words over who will, or will not, cut which services or increase which taxes in order to make the books balance and still undertake public spending. In this context one may confidently predict that the NHS will, in the rhetoric, fare reasonably well. Yet there also has to be a sense of realistic foreboding that 'something will have to go'. We must all acknowledge in our heart of hearts that even if politicians manipulate the text, the story will remain the same. Simply put, on a national level and possibly on a personal level too, we will no longer be able to afford everything that we have been enjoying in recent years.

In the same way, deep down, I believe that there is a feeling that dentistry is a less important part of the NHS than many of the acute services. In an era when rationing of resources becomes necessary, would patients rather see a reduction in cardiac, renal, cancer and general surgical services or in oral care services? Be honest when you answer. However, there are two underlying factors to consider. Firstly that people do increasingly value their oral health and the part we play in maintaining and improving it; and that they can conceive that the scale of the cost is at least within their ability to pay if they really have to, compared with say, heart surgery or long term therapy for chronic conditions.

Politicians will also have this sense of the public thinking and it may therefore be that the treasury money available for dentistry will be amongst the candidates squeezed in the coming years, possibly decades, in order to get UK plc back on a firm fiscal footing. If that is the case, the flip-side may well be that more patients will, initially reluctantly, shrug and, comprehending the need for thrift, pay for dental care themselves. In short, in budgeting ahead we may realistically have to plan for less public funding and greater private investment in oral health once the dust of the hustings has settled.

There will be other potential casualties of spending restraint and if the current government is replaced, then its philosophy of state control and regulation may well be overtaken by a more laissez faire approach. 'Quango-bashing', while a verbal sport in electioneering, may become not only a convenient economic target for savings but a philosophical option of choice. The consequence here may be a sharp change in what seems to be layer on layer of committees, commissions, review bodies, regulators and regulators of regulators. If we cannot afford the basics, at least for a while, then are we really going to sanction spending money on what might reasonably be seen as bureaucratic niceties? Whither the juggernaut of the Health Care Commission on the one hand and the relatively smaller transit van of revalidation on the other, all of which come with a price tag that may be just too much to afford?

Wherever the nation puts its collective ' $x$ ' in the next twelve months it is certain that the landscape of dentistry will be altered and the sooner we begin to plan for that the better we will be placed to serve our patients, our teams and ourselves.

DOI: 10.1038/sj.bdj.2009.379 